\title{
Comparison of the clinical risk factors between Candida albicans and Candida non-albicans species for bloodstream infection
}

\author{
Katsumi Shigemura ${ }^{1,2}$, Kayo Osawa ${ }^{2}$, Takumi Jikimoto ${ }^{2}$, Hiroyuki Yoshida ${ }^{2}$, Brian Hayama ${ }^{3}$, Goh Ohji ${ }^{3}$, \\ Kentaro Iwata $^{3}$, Masato Fujisawa ${ }^{1}$ and Soichi Arakawa ${ }^{1,2}$
}

The purpose of this study is to investigate the risk factors and susceptibilities to antifungal agents of Candida albicans and Candida non-albicans species (spp.) in candidemia cases in Kobe University Hospital. We investigated all consecutive patients with candida bloodstream infection (BSI) from 2008-2013 for whose full data were available for analyses, examining clinical factors such as gender, general complications, postoperative status or susceptibilities to antifungal agents. These factors were also compared between Candida albicans spp. and Candida non-albicans by univariate and multivariate analyses. Univariate analyses showed a significantly higher rate of Candida non-albicans species BSI patients cancer (odds ratio (OR) (95\% confidence interval $(\mathrm{Cl}))=2.29(1.04-5.06)$ and $P=0.040)$, chemotherapy $(\mathrm{OR}=4.35(1.11-17.1)$ and $P=0.035)$, fluconazole (FLCZ) resistance (OR $=77.3(4.51-1324)$ and $P=0.003)$, and itraconazole (ITCZ) resistance $(\mathrm{OR}=15.6$ (5.39-45.1) and $P<0.001)$ and lower rate of underlying cardiovascular diseases $(O R=0.27(0.09-0.80)$ and $P=0.018)$ and postoperative status $(\mathrm{OR}=0.35(0.16-0.77)$ and $P=0.035)$ in than Candida albicans. Multivariate analyses demonstrated that Candida non-albicans spp. had significantly higher rate of chemotherapy (OR=4.44 (1.04-19.0) and $P=0.045), F L C Z$ resistance ( $O R=5.87(2.01-17.1)$ and $P=0.001)$, and ITCZ resistance $(O R=18.7(5.77-60.4)$ and $P<0.001)$ and lower rate of underlying cardiovascular diseases $(\mathrm{OR}=0.25(0.08-0.82)$ and $P=0.022)$ than Candida albicans. In conclusion, this study revealed several risk factors for BSI with Candida albicans (underlying cardiovascular diseases and postoperative status) and Candida non-albicans spp. (cancer and chemotherapy), and demonstrated that Candida non-albicans spp. were more resistant to FLCZ and ITCZ than Candida albicans.

The Journal of Antibiotics (2014) 67, 311-314; doi:10.1038/ja.2013.141; published online 15 January 2014

Keywords: bloodstream infection; Candida albicans; Candida species; candidemia; risk factor

\section{INTRODUCTION}

Candida infections tend to emerge in immune-compromised hosts with dosing such as steroids, immune suppressants or chemotherapy. ${ }^{1-3}$ However, although immune-compromised status is a risk factor for Candida infection, some patients with normal immune states may have a Candida infection. ${ }^{4,5}$ Bloodstream infections (BSIs) with Candida species become easily fatal not only in immunecompromised hosts but also in those with normal immune status. The number of such infections is increasing, especially in intensive care units (ICUs) patients. ${ }^{6-8}$ The clinical risk factors for BSIs with Candida need to be understood for the prevention of mortality associated with Candida BSIs.

Candida spp. are basically classified into Candida albicans and Candida non-albicans. Krcmery and Barnes ${ }^{9}$ reported that
Candida non-albicans may cause more severe disease and higher mortality especially in BSI cases. The significant risk factors for severe Candida BSIs from Candida albicans and Candida non-albicans need to be differentiated.

In this study, we investigated the characteristics of BSIs with Candida spp. in our consecutive cases over a 5-year period at Kobe University Hospital, Kobe, Japan, and discriminated between the risk factors for Candida albicans spp. and Candida non-albicans BSIs especially focusing on investigation of Candida non-albicans spp., which in general tend to show more resistance to antifungal agents. We also examined the resistance to antifungal agents such as amphotericin B (AMPH), miconazole (MCZ), micafungin (MCFG), flucytosin (5-FC), fluconazole (FLCZ), itraconazole (ITCZ) and voriconazole (VRCZ).

\footnotetext{
${ }^{1}$ Division of Urology, Department of Organ Therapeutics, Kobe University Graduate School of Medicine, Kobe, Japan; ${ }^{2}$ Infection Control Team, Kobe University Hospital, Kobe, Japan and ${ }^{3}$ Division of Infectious Disease Therapeutics, Department of Microbiology and Infectious Diseases, Kobe University Graduate School of Medicine, Kobe, Japan Correspondence: Dr K Shigemura, Division of Urology, Department of Organ Therapeutics, Faculty of Medicine, Kobe University Graduate School of Medicine, 7-5-1 Kusunokicho, Chuo-ku, Kobe 650-0017, Japan.

E-mail: yutoshunta@hotmail.co.jp

Received 20 September 2013; revised 17 November 2013; accepted 2 December 2013; published online 15 January 2014
} 


\section{MATERIALS AND METHODS}

Patients

Candida species (spp.) were isolated from patients with BSIs from January 2008 to June 2013 in Kobe University Hospital (920 beds). We investigated the comparative clinical risk factors for Candida BSIs between Candida albicans and Candida non-albicans spp. and the susceptibilities of isolated fungi to representative antifungal agents. BSI was defined as symptomatic fungus isolation of one or more in $20 \mathrm{ml}$ blood. We recorded the patient's gender, age and clinical risk factors for Candida albicans or Candida non-albicans spp. causing BSI. Candida albicans BSI and Candida non-albicans BSI were defined as isolation of any species of Candida albicans or Candida non-albicans from at least one blood culture. In patients with more than one positive blood culture, only the first BSI was included. The detection of Candida spp. was performed using CHROMagar Candida (Japan BD Co. Ltd, Tokyo, Japan) and if necessary RapID Yeast plus kit (AMCO Incorporated, Tokyo, Japan). Risk factors included underlying cardiovascular diseases, liver-biliary-pancreatic disease, cancer-bearing, diabetes mellitus, steroid dosing and chronic renal failure. Antifungal agents tested were AMPH, MCZ, MCFG, 5-FC, FLCZ, ITCZ and VRCZ. The study was retrospectively performed with methods based on the Helsinki Declaration.

\section{Susceptibility testing}

Antifungal agent susceptibilities were tested and the results were interpreted and reported using the reference broth microdilution method as described by the Clinical and Laboratory Standards Institute (CLSI) M27-S3 (2010 CLSI Document M100-S20). The minimal inhibitory concentration was defined as the lowest antimicrobial concentration that totally inhibited bacterial growth. Susceptibilities were evaluated by CLSI category. We tested Candida strains against AMPH, MCZ, MCFG, 5-FC, FLCZ, ITCZ and VRCZ antifungal agents using drug susceptibility test kits for yeast-like fungus (ASTY) (Kyokuto Pharmaceutical Industrial Co. Ltd, Takahagi, Japan) after $48 \mathrm{~h}$ of culture. For quality control, Candida parapsilosis ATCC22019 or Candida Krusei ATCC6258 were used.

\section{Statistical analyses}

Statistical analysis was conducted using Fisher's exact test, Student's $t$-test, and univariate and multivariate logistic regression analysis with PASW Statistics 17.0 software packages (for Windows; SPSS Inc., Chicago, IL, USA). The latter two analyses were performed in order to seek for the odds ratio for comparison of extent of relationship between significant risk factors and Candida non-albicans BSI. Statistical significance was established at the 0.05 level.

\section{RESULTS}

\section{Patient characteristics}

There were 61 patients with Candida albicans BSIs and 49 patients with Candida non- albicans BSIs. The Candida non-albicans spp. isolated included 24 (49\%) Candida parapsilosis, 14 (29\%) Candida glabrata, 6 (12\%) Candida tropicalis, 2 (4\%) Candida guilliermondii, 1 (2\%) Candida stellatoidea, 1 (2\%) Candida krusei and 1 (2\%) other Candida spp. Patients included 74 males and 36 females, and 62 patients were age $>70$. Cardiovascular diseases, liver-biliarypancreatic disease, cancer, diabetes mellitus, steroid dosing, chronic renal failure, postoperative status, death, chemotherapy and radiation therapy were noted in $23,24,40,20,8,16,49,18,12$ and 2 cases, respectively. The susceptibility ratios to antifungal agents were 100 , 100, 100, 97.3, 82.7, 40.0 and 94.5\% for AMPH, MCZ, MCFG, 5-FC, FLCZ, ITCZ and VRCZ, respectively (Table 1).

\section{Comparison between Candida albicans BSIs and Candida non- albicans BSIs}

The comparison data between Candida albicans and Candida nonalbicans spp. showed that BSI patients with Candida albicans had older age and a higher ratio of underlying cardiovascular diseases
Table 1 Characteristics of Candida albicans and Candida nonalbicans in bloodstream infection cases

\begin{tabular}{|c|c|c|c|c|c|}
\hline \multirow[b]{2}{*}{ Patient characteristic } & \multicolumn{2}{|c|}{ Candida albicans } & \multicolumn{2}{|c|}{ Candida non-albicans } & \multirow[b]{2}{*}{ P-value } \\
\hline & $n$ & $\%$ & $n$ & $\%$ & \\
\hline Number & 61 & & 49 & & \\
\hline $\begin{array}{l}\text { Gender } \\
\text { Male } \\
\text { Female }\end{array}$ & $\begin{array}{l}39 \\
22\end{array}$ & $\begin{array}{l}63.9 \\
36.1\end{array}$ & $\begin{array}{l}35 \\
14\end{array}$ & $\begin{array}{l}71.4 \\
28.6\end{array}$ & $0.423^{a}$ \\
\hline $\begin{array}{l}\text { Age } \\
\text { Mean } \pm \text { S.D. } \\
\leqslant 70 \\
70<\end{array}$ & $\begin{array}{l}23 \\
38\end{array}$ & $\begin{array}{l}(69.7 \pm 15.2) \\
37.7 \\
62.3\end{array}$ & $\begin{array}{l}25 \\
24\end{array}$ & $\begin{array}{c}(63.2 \pm 18.9) \\
51.0 \\
49.0\end{array}$ & $\begin{array}{l}0.048^{\mathrm{b}} \\
0.180^{\mathrm{a}}\end{array}$ \\
\hline $\begin{array}{l}\text { Cardiovascular diseas } \\
\begin{array}{l}(-) \\
(+)\end{array}\end{array}$ & $\begin{array}{l}43 \\
18\end{array}$ & $\begin{array}{l}70.5 \\
29.5\end{array}$ & $\begin{array}{r}44 \\
5\end{array}$ & $\begin{array}{l}89.8 \\
10.2\end{array}$ & $0.018^{a}$ \\
\hline $\begin{array}{l}\text { Liver-biliary-pancreat } \\
\qquad \begin{array}{l}(-) \\
(+)\end{array}\end{array}$ & $\begin{array}{l}c \text { dis } \\
48 \\
13\end{array}$ & $\begin{array}{r}\text { ases } \\
78.7 \\
21.3\end{array}$ & $\begin{array}{l}38 \\
11\end{array}$ & $\begin{array}{l}77.6 \\
22.4\end{array}$ & $1.000^{\mathrm{a}}$ \\
\hline $\begin{array}{l}\text { Cancer } \\
(-) \\
(+)\end{array}$ & $\begin{array}{l}44 \\
17\end{array}$ & $\begin{array}{l}72.1 \\
27.9\end{array}$ & $\begin{array}{l}26 \\
23\end{array}$ & $\begin{array}{l}53.1 \\
46.9\end{array}$ & $0.047^{a}$ \\
\hline $\begin{array}{l}\text { Diabetes mellitus } \\
\left(\begin{array}{l}(-) \\
(+)\end{array}\right.\end{array}$ & $\begin{array}{r}52 \\
9\end{array}$ & $\begin{array}{l}85.2 \\
14.8\end{array}$ & $\begin{array}{l}38 \\
11\end{array}$ & $\begin{array}{l}77.6 \\
22.4\end{array}$ & $0.329^{a}$ \\
\hline $\begin{array}{l}\text { Steroid dosing } \\
(-) \\
(+)\end{array}$ & $\begin{array}{r}57 \\
4\end{array}$ & $\begin{array}{r}93.4 \\
6.6\end{array}$ & $\begin{array}{r}45 \\
4\end{array}$ & $\begin{array}{r}91.8 \\
8.2\end{array}$ & $1.000^{\mathrm{a}}$ \\
\hline $\begin{array}{l}\text { Chronic renal failure } \\
\begin{array}{l}(-) \\
(+)\end{array}\end{array}$ & $\begin{array}{r}52 \\
9\end{array}$ & $\begin{array}{l}85.2 \\
14.8\end{array}$ & $\begin{array}{r}42 \\
7\end{array}$ & $\begin{array}{l}85.7 \\
14.3\end{array}$ & $1.000^{\mathrm{a}}$ \\
\hline $\begin{array}{l}\text { Postoperative status } \\
\qquad \begin{array}{l}(-) \\
(+)\end{array}\end{array}$ & $\begin{array}{l}27 \\
34\end{array}$ & $\begin{array}{l}44.3 \\
55.7\end{array}$ & $\begin{array}{l}34 \\
15\end{array}$ & $\begin{array}{l}69.4 \\
30.6\end{array}$ & $0.012^{\mathrm{a}}$ \\
\hline $\begin{array}{r}\text { Death } \\
(-) \\
(+)\end{array}$ & $\begin{array}{l}51 \\
10\end{array}$ & $\begin{array}{l}83.6 \\
16.4\end{array}$ & $\begin{array}{r}41 \\
8\end{array}$ & $\begin{array}{l}83.7 \\
16.3\end{array}$ & $1.000^{\mathrm{a}}$ \\
\hline $\begin{array}{l}\text { Chemotherapy } \\
(-) \\
(+)\end{array}$ & $\begin{array}{r}58 \\
3\end{array}$ & $\begin{array}{r}95.1 \\
4.9\end{array}$ & $\begin{array}{r}40 \\
9\end{array}$ & $\begin{array}{l}81.6 \\
18.4\end{array}$ & $0.032^{\mathrm{a}}$ \\
\hline $\begin{array}{l}\text { Radiation therapy } \\
\begin{array}{l}(-) \\
(+)\end{array}\end{array}$ & $\begin{array}{r}59 \\
2\end{array}$ & $\begin{array}{r}96.7 \\
3.3\end{array}$ & $\begin{array}{r}49 \\
0\end{array}$ & $\begin{array}{r}100.0 \\
0.0\end{array}$ & $0.501^{a}$ \\
\hline $\begin{array}{l}5-F C \\
S^{*} \\
I \& R\end{array}$ & $\begin{array}{r}60 \\
1\end{array}$ & $\begin{array}{r}98.4 \\
1.6\end{array}$ & $\begin{array}{r}47 \\
2\end{array}$ & $\begin{array}{r}95.9 \\
4.1\end{array}$ & $0.585^{a}$ \\
\hline $\begin{array}{l}F L C Z \\
\text { S } \\
\text { I\&R }\end{array}$ & $\begin{array}{r}61 \\
0\end{array}$ & $\begin{array}{r}100.0 \\
0.0\end{array}$ & $\begin{array}{l}30 \\
19\end{array}$ & $\begin{array}{l}61.2 \\
38.8\end{array}$ & $<0.001^{a}$ \\
\hline $\begin{array}{l}\text { ITCZ } \\
\text { S } \\
\text { I\&R }\end{array}$ & $\begin{array}{l}39 \\
22\end{array}$ & $\begin{array}{l}63.9 \\
36.1\end{array}$ & $\begin{array}{r}5 \\
44\end{array}$ & $\begin{array}{l}10.2 \\
89.8\end{array}$ & $<0.001^{a}$ \\
\hline $\begin{array}{l}V R C Z \\
\mathrm{~S} \\
\text { I\&R }\end{array}$ & $\begin{array}{r}61 \\
0\end{array}$ & $\begin{array}{r}100.0 \\
0.0\end{array}$ & $\begin{array}{r}43 \\
6\end{array}$ & $\begin{array}{l}87.8 \\
12.2\end{array}$ & $0.007^{a}$ \\
\hline
\end{tabular}

Bold: statistically significant, $\mathrm{S}^{*}$ : susceptible, I: intermediate, $\mathrm{R}$ : resistant aFisher's exacttest

'Student's T-test

( $P=0.018)$ and postoperative status $(P=0.009)$ and those with Candida non-albicans spp. had a higher ratio of cancer $(P=0.040)$ and chemotherapy $(P=0.035)$. Resistance to antifungal agents was 
Table 2 Results of univariate and multivariate logistic regression analyses of risk factors associated with Candida non-albicans BSIs

\begin{tabular}{|c|c|c|c|c|}
\hline \multirow[b]{2}{*}{ Risk factors } & \multicolumn{2}{|c|}{ Univariate } & \multicolumn{2}{|c|}{ Multivariate } \\
\hline & Odds ratio $(95 \% \mathrm{Cl})$ & $\mathrm{P}$-value & Odds ratio $(95 \% \mathrm{Cl})$ & P-value \\
\hline Gender (female) & $0.71(0.31-1.60)$ & 0.406 & $0.58(0.24-1.36)$ & 0.209 \\
\hline Age $(70<)$ & $0.58(0.27-1.25)$ & 0.163 & $0.74(0.33-1.68)$ & 0.471 \\
\hline Cardiovascular diseases & $0.27(0.09-0.80)$ & 0.018 & $0.25(0.08-0.82)$ & 0.022 \\
\hline Liver-biliary-pancreatic diseases & $1.07(0.43-2.65)$ & 0.886 & $0.74(0.28-1.95)$ & 0.538 \\
\hline Cancer & $2.29(1.04-5.06)$ & 0.040 & $2.14(0.83-5.50)$ & 0.120 \\
\hline Diabetes mellitus & $1.67(0.63-4.44)$ & 0.301 & $1.67(0.61-4.58)$ & 0.324 \\
\hline Steroid dosing & $1.27(0.30-5.35)$ & 0.748 & $1.20(0.24-5.95)$ & 0.823 \\
\hline Chronic renal failure & $0.96(0.33-2.80)$ & 0.945 & $0.98(0.31-3.15)$ & 0.977 \\
\hline Postoperative status & $0.35(0.16-0.77)$ & 0.009 & $0.53(0.21-1.35)$ & 0.182 \\
\hline Death & $1.00(0.36-2.75)$ & 0.992 & $1.05(0.35-3.11)$ & 0.935 \\
\hline Chemotherapy & $4.35(1.11-17.1)$ & 0.035 & $4.44(1.04-19.0)$ & 0.045 \\
\hline Radiation therapy & $0.94(0.08-11.8)$ & 0.960 & $0.38(0.03-4.58)$ & 0.450 \\
\hline 5-FC resistant & $2.55(0.23-29.0)$ & 0.450 & $3.45(0.27-44.0)$ & 0.340 \\
\hline FLCZ resistant & $77.3(4.51-1324)$ & 0.003 & $5.87(2.01-17.1)$ & 0.001 \\
\hline ITCZ resistant & $15.6(5.39-45.1)$ & $<0.001$ & $18.7(5.77-60.4)$ & $<0.001$ \\
\hline VRCZ resistant & $17.0(0.93-312)$ & 0.056 & $3.64(0.73-18.1)$ & 0.115 \\
\hline
\end{tabular}

Stastically significant values are indicated in bold.

higher in FLCZ $(P=0.003)$ and ITCZ $(P<0.001)$ in Candida nonalbicans spp. than Candida albicans (Table 1).

\section{Risk Factors for Candida non-albicans BSIs compared with} Candida albicans BSIs

Univariate analyses showed that Candida non-albicans species had significantly higher rate in patients with cancer (odds ratio (OR) $(95 \%$ confidence interval $(\mathrm{CI}))=2.29(1.04-5.06)$ and $P=0.040)$, chemotherapy $(\mathrm{OR}=4.35(1.11-17.1)$ and $P=0.035)$, FLCZ resistance $(\mathrm{OR}=77.3(4.51-1324)$ and $P=0.003)$ and ITCZ resistance $(\mathrm{OR}=15.6(5.39-45.1)$ and $P<0.001)$ and a lower rate of underlying cardiovascular diseases $(\mathrm{OR}=0.27(0.09-0.80)$ and $P=0.018)$ and postoperative status $(\mathrm{OR}=0.35(0.16-0.77)$ and $P=0.035)$ than Candida albicans. Multivariate analyses demonstrated that Candida non-albicans spp. had significantly higher rates of chemotherapy $(\mathrm{OR}=4.44(1.04-19.0)$ and $P=0.045), F L C Z$ resistance $(\mathrm{OR}=5.87$ (2.01-17.1) and $P=0.001)$ and ITCZ resistance $(\mathrm{OR}=18.7$ (5.77$60.4)$ and $P<0.001)$ and a lower rate of underlying cardiovascular diseases $(\mathrm{OR}=0.25(0.08-0.82)$ and $P=0.022)$ than Candida albicans (Table 2).

\section{DISCUSSION}

One of the main findings of this study was a significantly higher rate of Candida non-albicans species in BSI patients with cancer, chemotherapy, FLCZ resistance and ITCZ resistance, and lower rate of underlying cardiovascular diseases and postoperative status than Candida albicans. Multivariate analyses demonstrated that Candida non-albicans spp. had significantly higher rate of chemotherapy, FLCZ resistance and ITCZ resistance, and lower rate of underlying cardiovascular diseases than Candida albicans. Regarding the risk factors for Candida BSIs, Ma et al. ${ }^{10}$ showed that complicated abdominal surgery, presence of central venous catheter, neutropenia and Candida tropicalis were seen at significantly higher rates and treatment with FLCZ were fewer in the mortality group than the survival group in their comparison analyses, and central venous catheter was an independent risk factor for a 30-day Candida BSI mortality by multivariate analyses. On the other hand, increases in common risk factors such as ICU admission, ${ }^{11,12}$ or immunosuppressive therapies ${ }^{13}$ may have resulted in an increase in the overall pool of patients at high risk for candidemia. Our suggested significant risk factors for Candida non-albicans BSIs demonstrated a significantly higher rate of chemotherapy than Candida albicans in multivariate analyses, which agrees with these previous works.

Regarding antifungal therapy, Ha et al. ${ }^{14}$ reported that treatment failure of first-line antifungal drugs was associated with 30-day mortality and salvage therapy using VRCZ for the treatment of candidemia in patients intolerant of or refractory to other antifungal agents was reported to be successful. ${ }^{15}$ VRCZ may be a suitable agent for salvage therapy for invasive candidiasis, even in the setting of previous azole exposure and Candida krusei infection. ${ }^{16,17}$ Our current data showed that FLCZ and ITCZ were independent risk factors for Candida non-albicans BSIs. Taken together, these studies suggest it may be necessary to predict the causative Candida (Candida albicans or Candida non-albicans) based on the suggested risk factors in order to avoid treatment failure.

Chow et al. ${ }^{18}$ showed that ICU patients had a major pre-ICU operation, total parenteral nutrition duration, hemodialysis duration, mean number of red blood cell (RBC) transfusions per day, gastrointestinal procedure, and enteric bacteremia were risk factors for Candida non-albicans spp. BSIs, with total parenteral nutrition duration per days at risk, hemodialysis duration per days at risk, major operation during ICU stay and enteric bacteremia were risk factors for Candida non-albicans spp. BSIs in their multivariate analyses. While the differences between our study comparing Candida albicans spp. and Candida non-albicans BSIs and the previous study make direct comparison difficult, our data on risk factors for Candida BSIs are useful for the understanding and predicting the outcome of these infections.

From a mycological aspect, clinically important Candida spp. are subgrouped into albicans, grabrata, parapsilosis, tropicalis, guilliermondii or krusei and can be generally categorized as Candida albicans and Candida non-albicans spp. for investigative purposes. ${ }^{19}$ The epidemiology of Candida BSIs appears to be changing and especially the proportion of Candida non-albicans BSIs has been 
increasing. ${ }^{20-25}$ We designed this study to discriminate between Candida albicans spp. and Candida non-albicans, and demonstrated that underlying cardiovascular diseases and postoperative status were significant risk factors for Candida albicans BSI and cancer and chemotherapy for Candida non-albicans spp. BSI. The information of the difference of the clinical risk factors between Candida albicans and Candida non-albicans BSIs may be useful to the physicians who take care of Candida patients because the susceptibilities to antifungal agents were different between them. That is, Candida non-albicans spp. BSIs showed a higher resistance ratio to FLCZ and ITCZ than Candida albicans BSIs, taken together with the risk factor data mentioned above, has implications for first-line treatments of Candidal BSI.

We would like to emphasize the limitations of this study. First, the number of cases was not enough for definitive conclusions although they do represent all the consecutive cases in our institution, Kobe University Hospital, over the last 5 years. Second, we lacked a control group for comparison, unlike previous studies. ${ }^{18,19}$ Third, the potential risk factors we investigated may not be comprehensive and did not include some risk factors assessed in other studies. These limitations will be addressed in our future work.

In conclusion, this study differentiated several risk factors for BSI with Candida albicans (underlying cardiovascular diseases and postoperative status) and Candida non-albicans spp. (cancer and chemotherapy), and demonstrated that Candida non-albicans spp. were more resistant to FLCZ and ITCZ than Candida albicans. These findings might be affected by Candida epidemiology in our University Hospital.

1 Bukhary, Z. A. Candiduria: a review of clinical significance and management. Saudi J. Kidney Dis. Transpl. 19, 350-360 (2008).

2 Wise, G. J. \& Silver, D. A. Fungal infections of the genitourinary system. J. Urol. 149, 1377-1388 (1993).

3 Wainstein, M. A., Graham, R. C. Jr \& Resnick, M. I. Predisposing factors of systemic fungal infections of the genitourinary tract. J. Urol. 154, 160-163 (1995).

4 Reagan, D. R., Pfaller, M. A., Hollis, R. J. \& Wenzel, R. P. Characterization of the sequence of colonization and nosocomial candidemia using DNA fingerprinting and a DNA probe. J. Clin. Microbiol. 28, 2733-2738 (1990).

5 Toya, S. P., Schraufnagel, D. E. \& Tzelepis, G. E. Candiduria in intensive care units: association with heavy colonization and candidaemia. J. Hosp. Infect. 66, 201-206 (2007).
6 Clark, T. A. et al. Epidemiologic and molecular characterization of an outbreak of Candida parapsilosis bloodstream infections in a community hospital. J. Clin. Microbiol. 42, 4468-4472 (2004).

7 Ostrosky-Zeichner, L. \& Pappas, P. G. Invasive candidiasis in the intensive care unit. Crit. Care Med. 34, 857-863 (2006).

8 Beck-Sague, C. \& Jarvis, W. R. Secular trends in the epidemiology of nosocomial fungal infections in the United States, 1980-1990. National Nosocomial Infections Surveillance System. J. Infect. Dis. 167, 1247-1251 (1993).

9 Krcmery, V. \& Barnes, A. J. Non-albicans Candida spp. causing fungaemia: pathogenicity and antifungal resistance. J. Hosp. Infect. 50, 243-260 (2002).

$10 \mathrm{Ma}, \mathrm{C}$. F. et al. Surveillance study of species distribution, antifungal susceptibility and mortality of nosocomial candidemia in a tertiary care hospital in China. BMC Infect. Dis. 13, 337 (2013).

11 Lerolle, N. et al. Increased intensity of treatment and decreased mortality in elderly patients in an intensive care unit over a decade. Crit. Care Med. 38, 59-64 (2010).

12 Halpern, N. A. \& Pastores, S. M. Critical care medicine in the United States 2000-2005: an analysis of bed numbers, occupancy rates, payer mix, and costs. Crit. Care Med. 38, 65-71 (2010).

13 Giri, S. \& Kindo, A. J. A review of Candida species causing bloodstream infection. Indian J. Med. Microbiol. 30, 270-278 (2012).

$14 \mathrm{Ha}, \mathrm{Y}$. E. et al. Impact of first-line antifungal agents on the outcomes and costs of candidemia. Antimicrob. Agents Chemother. 56, 3950-3956 (2012).

15 Ostrosky-Zeichner, L., Lashof, A. O., Kullberg, B. J. \& Rex, J. H. Voriconazole salvage treatment of invasive candidiasis. Eur. J. Clin. Microbiol. Infect. Dis. 22, 651-655 (2003).

16 Peman, J., Canton, E. \& Gobernado, M. Spanish ECMM Working Group on Candidaemia. Epidemiology and antifungal susceptibility of Candida species isolated from blood: results of a 2-year multicentre study in Spain. Eur. J. Clin. Microbiol. Infect. Dis 24, 23-30 (2005).

17 Muñoz, P. et al. Candida krusei fungaemia: antifungal susceptibility and clinical presentation of an uncommon entity during 15 years in a single general hospital. J. Antimicrob. Chemother. 55, 188-193 (2005).

18 Chow, J. K. et al. Risk factors for albicans and non-albicans candidemia in the intensive care unit. Crit. Care Med. 36, 1993-1938 (2008).

19 Chow, J. K. et al. Factors associated with candidemia caused by non-albicans Candida species versus Candida albicans in the intensive care unit. Clin. Infect. Dis. 46, 1206-1213 (2008)

20 Pfaller, M. A., Jones, R. N., Messer, S. A., Edmond, M. B. \& Wenzel, R. P. Surveillance and Control of Pathogens of Epidemiologic. Diagn. Microbiol. Infect. Dis. 30, 121-129 (1998).

$21 \mathrm{Kao}, \mathrm{A}$. S. et al. The epidemiology of candidemia in two United States cities: results of a population-based active surveillance. Clin. Infect. Dis. 29, 1164-1170 (1999).

22 Baran, J. Jr, Muckatira, B. \& Khatib, R. Candidemia before and during the fluconazole era: prevalence, type of species and approach to treatment in a tertiary care community hospital. Scand. J. Infect. Dis. 33, 137-139 (2001).

$23 \mathrm{Abi}$-Said, D. et al. The epidemiology of hematogenous candidiasis caused by different Candida species. Clin. Infect. Dis. 24, 1122-1128 (1997).

24 Trick, W. E. et al. Secular trend of hospital-acquired candidemia among intensive care unit patients in the United States during 1989-1999. Clin. Infect. Dis. 35, 627-630 (2002).

25 Pappas, P. G. et al. A prospective observational study of candidemia: epidemiology, therapy, and influences on mortality in hospitalized adult and pediatric patients. Clin. Infect. Dis. 37, 634-643 (2003). 